JOURNAL OF SECURITY AND SUSTAINABILITY ISSUES

ISSN 2029-7017/ISSN 2029-7025 (online)

2020 Volume 9 January

http://doi.org/10.9770/jssi.2020.9.3(20)

\title{
IMPACT OF HR-LINKED QUALITY ASSURANCE SYSTEM ON OPERATIONAL PROFICIENCY
}

\author{
Chayanan Kerdpitak ${ }^{1}$, Chanathat Boonrattanakittibhumi² \\ ${ }^{I}$ Graduate School, Suan Sunandha Rajabhat University, Bangkok, Thailand \\ ${ }^{2}$ King Mongkut's Institute of Technology Ladkrabang Prince of Chumphon Campus, Chumphon, Thailand \\ E-mail: ${ }^{1}$ chayanan.ke@ssru.ac.th; ${ }^{2}$ b.dr.chanathat2013@gmail.com (Corresponding author)
}

Received 19 March 2019; accepted 12 December 2019; published 30 January 2020

\begin{abstract}
The purpose of this study is to embrace the theoretical context of operational proficiency and accordingly examines the connection between human resource-linked with quality assurance system and development of novel product taking with the consideration to operational proficiency, learning system, knowledge assimilation, and strategic adaptability. Learning system and knowledge assimilation are correlated with strategic adaptability of an organization, and strategic adaptability is the established capability, which enables development of novel product. In order to empirically examine the connection, data was gathered from ASEAN organizations and structural equation modeling was carried out. Findings reveal that human resource connected with quality assurance system facilitate in establishing learning focused organization, unifying knowledge and assists in development of novel product. Moreover, Unification of knowledge is progressively associated with development of new product via strategic adaptability.
\end{abstract}

Reference to this paper should be made as follows: Kerdpitak, C., Chanathat Boonrattanakittibhumi, C. 2020. Impact of HR-linked quality assurance system on operational proficiency. Journal of Security and Sustainability Issues, 9(January), 264-280.

http://doi.org/10.9770/jssi.2020.9.3(20)

JEl Classifications: O15, O20

\section{Introduction}

In this age of industrialization, researchers, specialists and practitioners are all in consensus in glorifying quality assurance system as a key variable in gaining competitive edge, at the same time positively influencing organizational performance (Jermsittiparsert, Namdej, \& Somjai, 2019). Nevertheless, the vitality and intricacy of modern business settings (Teece, 2018), does not guarantee that organization maintaining superior quality at a certain time period will be able to endure the same quality level and position at different time period. Companies like Samsung, Toyota, and Apple have found it difficult managing the challenges associated with performance over a long period of time (Su, Linderman, 2016).

Companies looking forward to maintain their position through altering their existing system with respect to the prevailing environmental norms (Teece, 2018; Vegera, Malei, Trubovich, 2018; Cardoso, Swan, Mendes, 2018; Moumen, El Idrissi, Tvaronavičienè, Lahrach, 2019), it is imperative to not only explore the field of quality assurance system and its influence on the organizational performance but to discover whether quality assurance application is connected with strategic variables of the organization and how it can support in enhancing strategic capacity of the organization. Operational proficiency viewpoint assists as a very adequate context, which provides the bases for examining the association amidst quality assurance and strategic variables connected with acclimatizing with environment. Davies, Dodgson, Gann (2016) have defined operational proficiency as the capability of an organization that aid them articulating a strategy to respond to the environmental modifications; ultimately assisting organization maintaining their position. 
JOURNAL OF SECURITY AND SUSTAINABILITY ISSUES

ISSN 2029-7017/ISSN 2029-7025 (online)

2020 Volume 9 January

http://doi.org/10.9770/jssi.2020.9.3(20)

The process in which organization modifies its operational procedures, overall structure, culture and technology, as well as the bearing effect these modifications has on the organization is called organizational changes. Organizational changes also require nurturing a learning as well as knowledge sharing environment where employees can easily adjust with modification. It becomes evidently important for Human resource to initiate programs which facilitates employees of the organization to not only explore but also apply their experience and knowledge which further cultivate ingenuity and stimulate organization towards new opportunities (Prajogo, Oke, 2016). Therefore, HR needs to provide the basic groundwork based on that; operational proficiency of an organization can be materialized which is then connected with development of novel product (Hsiao-Yun Liang et al., 2015). This diverse approach of HR connected with quality assurance system can go long way in making organization more penetrating to the disparities of the environment, it will be supple strategically and accordingly will be able to embrace the variation efficiently.

Research studies in connection to HR-linked with quality assurance system, and precisely emphasizing the quality aspect as rarely been experientially investigated with the consideration to operational proficiency viewpoint. It is difficult to find a unified structure with respect to quality assurance and operational proficiency in existing literature backed up by experiential results which recognize the importance of HR-linked with quality assurance system in establishing operational proficiency namely development of novel product or enhancing strategic capacity. Therefore the novelty of the study in hand signifies the importance of integrating quality assurance with operational proficiency context (Su, Linderman, 2016) and filling the vacuum of existing literature by experientially examining the connection between HR-linked with quality assurance system, strategic adaptability and development of novel product.

Research paper also expand the existing literature by classifying the practices associated with HR-linked quality assurance which stimulates organization to expand their transformation capacity including strategic adaptability, which help them in establishing differentiating factor with respect to development of novel product. To this point research concerning HR operations and their implications on the managers have not included the operational proficiency perspective (Garavan, Shanahan, Carbery \& Watson, 2016). Therefore, research paper in hand provides valuable insight to the managers as it endorses methods through which quality assurance system can be applied efficiently and allows organization embrace changes strategically and established a set pattern for the development of novel product recurrently.

In order to examine the expansion of operational proficiency of an organization, development of novel product was conceptualizing as operational proficiency. Often researchers have striven to illustrate the concept of operational proficiency via practices associated with developing novel product which highlights the procedure through which organization rearrange their resources as well as ability in order to efficiently counter to the environmental changes (Schilke, 2014). Different organization responds to their environment differently, same rule cannot be applied to every organization, Samsung, Apple, Gillette to name a few have counter their environment aggressively and accordingly enforce a certain pattern to their environment by creatively expanding their product range (Danneels \& A Vestal, 2018). Similarly, development of novel product can be linked with quality assurance. Organization that have high quality measures are expected to have firm bases in order to execute plan related to development of novel product. Specifically, HR-linked quality assurance system enables smooth information and knowledge sharing, well defined responsibilities and accountability measures and lastly gives employees the freedom to experiment; this all lead to improve and creative operations.

Findings from previous studies have revealed vague results regarding connection between quality assurance and ingenuity (Prajogo, 2016). Results from the research paper in hand have specify that there is progressive connection 
JOURNAL OF SECURITY AND SUSTAINABILITY ISSUES

ISSN 2029-7017/ISSN 2029-7025 (online)

2020 Volume 9 January

http://doi.org/10.9770/jssi.2020.9.3(20)

between quality assurance and ingenuity; offering experiential proof to support the study that verify the presence of the connection.

\section{Rational Consequences}

Research paper is very much pertinent with specialist as it highlights important elements concerning quality assurance execution, which facilitates organizations to be further strategic adaptable, consequently enhanced ability to frequently invest in novel product.

\section{Originality}

In this modern age, it is imperative for organization to maintain their competitive edge by constantly acclimatizing with environmental modifications; existing literature is filled with studies where researchers have tried to gauge the impact of quality assurance system on the performance of the organization but little focus has been given where quality assurance application has been linked with strategic variables and ultimately assist in the operational process of an organization strategically. This study suggests a unified structure with the help of empirical study that recognizes the role of human resource-linked with quality assurance system in relation learning system, knowledge assimilation, strategic adaptability and lastly development of novel product.

\section{Literature Review}

Operational proficiency perspective can be linked with acknowledged resource-based view which suggests that organization resources and its diverse nature very much define the likelihood of attaining viable competitive edge (Barney, 1991). In this age of modernization where it is difficult to accurately anticipate the vibrant as well as unsettled environment, many scholars and practitioners have challenge the theory of resource based view and asked to spend the scope of theory by adding operational proficiency in the overall perspective (Pisano, 2017). Operational proficiency is the ability of an organization which facilitates in assimilation, construction and rearrangement of internal expertise in order to adapt with swiftly altering environment (Pisano, 2017). In this context, operational proficiency permits organization to continuously restructure their resources which allow organization to adjust with the environment efficiently.

Practitioners and scholars have been continuously exploring the field of operational proficiency and have highlighted a course which they regard a very precise way to respond to the vitality of the environment (Schilke, 2014). Petrus (2019) initially suggested wide ranging activities that can be related with operational proficiency which include product development, collaborations, information \& knowledge sharing, mergers to name a few. Nevertheless, when operational proficiency was further studies it was identified that collaboration capacity and development of new product were the two broadly accepted characteristic associated with operational proficiency which allows organization to efficiently adjust with environmental changes. Precisely these activities assist in comprehending the role of operational proficiency as superior process which affects other competencies of an organization. Hence, it is imperative for organization to maintain their production, marketing and circulation facility which facilitate in conserving their present state of affairs. Yet initiating a novel product development or participating in collaboration can activate a series rearrangement of resources, as well as resettling other routine facilities of an organization (Wilden, Gudergan, 2015). Previous studies also acknowledge the fact that more often than not managers engage in development of novel product in order to counter as well adapt with the complexity of the environment. Launching a new product do requires number of initiatives that works as a trigger reconfiguring routine of an organization, at the same time affecting consumer behavior and competition; therefore, safeguarding flexibility with respect to environmental changes regardless of an industry. 
JOURNAL OF SECURITY AND SUSTAINABILITY ISSUES

ISSN 2029-7017/ISSN 2029-7025 (online)

2020 Volume 9 January

http://doi.org/10.9770/jssi.2020.9.3(20)

Researchers' keen interest to explore operational proficiency and specifically the mechanism behind operational proficiency has led to identification of potential process flow (Teece, 2018). Specifically, researchers and scholars have claimed that establishing operational proficiency do require organization to have absorptive capacity, information processing procedure and lastly knowledge management system. These components have been recognized by realizing the importance of concept 'organizational learning' which provides the required foundation to build operational proficiency as it provides the bases through which organization polish as well as update its knowledge system (Petrus, 2019). In order to improve their knowledge system, organization needs to nurture a culture, establish values and set principles which provide the required impetus in building knowledge-based structure. Therefore, efficient operational proficiency requires organization to be learning as well as knowledge oriented. Organizations that have exceptional operational proficiency have built this competency through continuous experimentation as well as by being inventive and learning from others, these organization have the audacity to take innovative measures and if they fail, they learn from their mistakes (Petrus, 2019). Besides operational proficiency, reform and polish the knowledge structure entrench in organizational practice; this necessitates composed series of action which facilitate in establishing equilibrium with respect to knowledge and learning system. Organization cannot establish efficient operational proficiency solely relying on learning system. Learning system has its importance, but it is also essential that it must be connected with knowledge management system as combination of both facilitate in decision making process. Similarly, this connection is also important as it serve as a link between the conception of new information and utilizing the existing information. This formation between learning system and knowledge management system fortifies organization capacity to perceive as well as react timely towards diverse environmental modifications; this also advocate link between learning system, knowledge management system and strategic adaptability (Baškarada, \& Koronios, 2018). All these antecedents very much outline the organization structure and operational proficiency like development of novel product is created to counter environmental modifications (Pisano, 2017).

Organizations need comprehensive approach in order to ensure that quality standards are met, for this purpose they need to develop a philosophy which is the guiding line that attempts for nonstop refinement of the overall operations of the organization (O'Neill, Sohal, \& Wei Teng, 2016). It depends on series of action which can influence every stakeholder of the organization, at the same time it will also affect technical arrangement of the organization. Smooth execution of these actions entails unifying perspective. While HR linked quality assurance measures cannot be associated directly with the organizational performance, but it has its significance. Through these measures organization can spread its vision more widely and encourages employee involvement which ultimately results in increased level of commitment from employees toward quality assurance and further simplifies the execution of technical aspect of quality assurance. Previous studies have also highlighted the significant role of human resources management during the execution quality assurance system (Quang et al., 2016). Focal point of the research paper in hand consists of three specific elements with respect to HR-linked quality assurance system which include employee training, empowering employees and lastly encouraging collaboration. The important of these elements have been widely accredited in past studies with respect to quality assurance (Shafiq, Lasrado, \& Hafeez, 2017; Prajogo, 2016; Kuchinke, 2017).

Activities related to HR have strategic significance as they very much organization specific and are difficult to emulate (Longoni, Cagliano, 2016; Boon, Den Hartog, \& Lepak, 2019). These HR practices are very much goal oriented and are very exclusive and significant, and are likely to improve performance of the organization (Boon, Hartog, \& Lepak, 2019; Gabriel, Cheshin, Moranc, \& van Kleef, 2015), by associating HR with quality assurance can be influential in setting high performance parameters. Literature associated with HR and its management advocates that these activities make meaningful assistance towards organization creative sense (Fay, Shipton, West, and Patterson, (2015); Lin, Sanders, Jian-Min, Shipton \& Mooi, 2018). One of the important HR attributes is training session for employees, which allow them to build their capabilities, improve knowledge and refine their 
JOURNAL OF SECURITY AND SUSTAINABILITY ISSUES

ISSN 2029-7017/ISSN 2029-7025 (online)

2020 Volume 9 January

http://doi.org/10.9770/jssi.2020.9.3(20)

skills; which ultimately translate into basis for innovative concepts, operations and practices for organization. Employees feel motivated when they are empowered, at the same time giving them the authority to make decision also trigger generation of new ideas, concepts and innovative possibilities for organization. Collaboration between employees as its significance, it helps establishing new ideas, motivates employees to share knowledge with each other and generates numerous courses of action, thus producing various possibilities. Collaboration also enables smooth exchange of knowledge between employees as it facilitates removing obstacles and nourishes communication, thereby aiding to inventiveness.

In context to above presented theory concerning different variables, following research prototype can be proposed (see Figure 1)

:

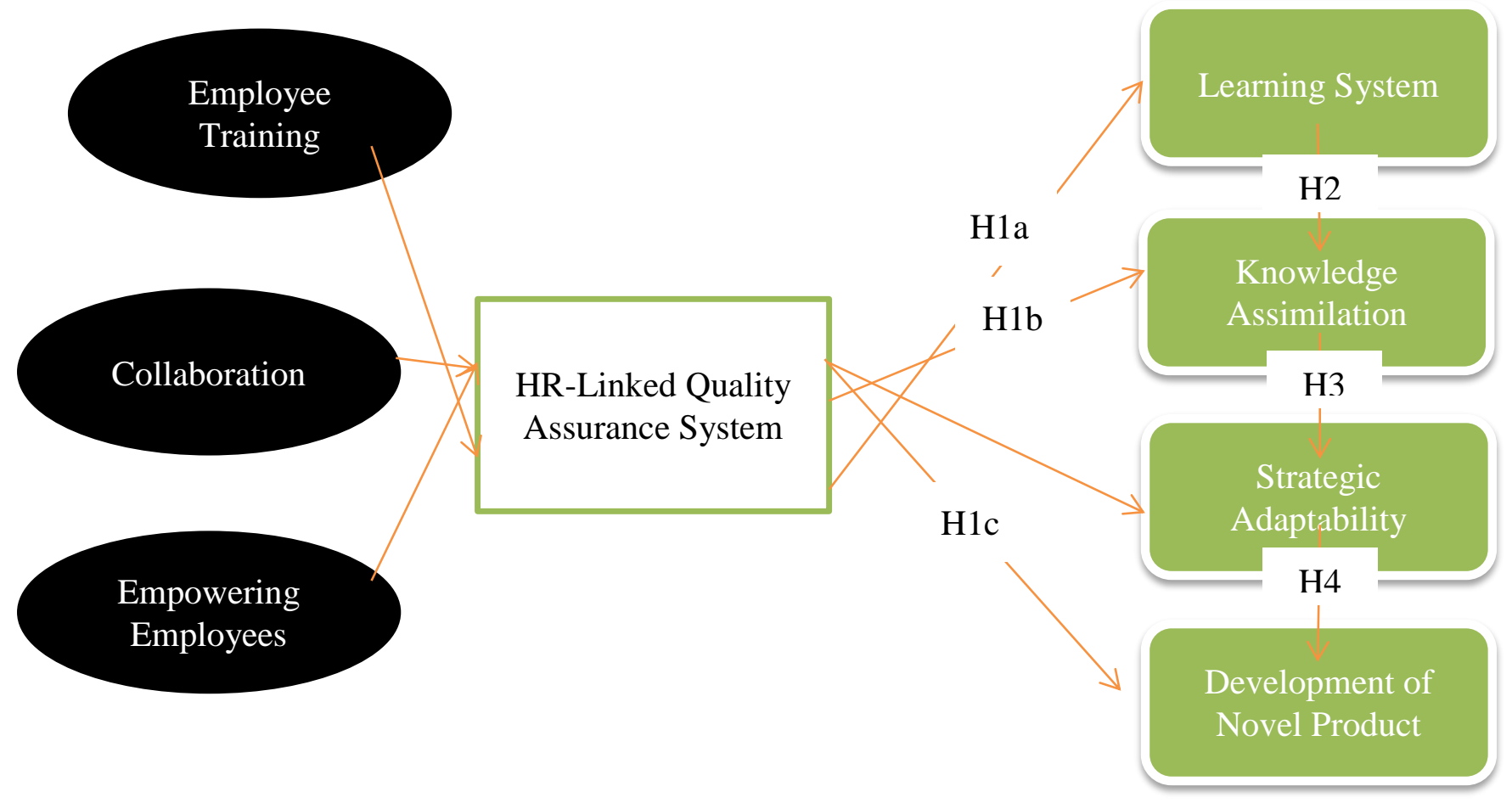

Figure 1. HR-linked Quality Assurance System

Learning System of an organization is very much connected with HR-linked quality assurance system. Training has a very significant effect on employees, it improves their ability to solve different problem which ultimately help towards learning system of an organization (Park \& Kim, 2018). Sessions conducted by manager connected with quality assurance system also encourage cerebral thinking, exploration, discussion and enthusiasm; which fortify the learning system of an organization (Khalil \& Mehmood, 2018). Empowering employees allow them to freely communicate and improve themselves (Zeng, Zhang, Matsui, Zhao, 2017), this change allow employees to freely share their ideas with others which ultimately effect the learning system (Bakotić \& Rogošić, 2017). Employee suggestion program and quality control circles related to collaboration allow efficient exchange of knowledge as well as its systemization, which is very much favorable in establishing an atmosphere, that nurture learning. Researchers have suggested that creating teams allows employees to socialize with each other, simplify exchange of knowledge, assist in the creation of ideas, and enables personnel to utilize existing knowledge (Al Ahbabi, Singh, Balasubramanian, \& Gaur, 2019). Additionally, collaboration between employees allows them to communicate and 
JOURNAL OF SECURITY AND SUSTAINABILITY ISSUES

ISSN 2029-7017/ISSN 2029-7025 (online)

2020 Volume 9 January

http://doi.org/10.9770/jssi.2020.9.3(20)

gauge possibilities with respect to their merit and demerits, thus signifying learning-based organization (Khalil \& Mehmood, 2018). Execution of HR-linked quality assurance system assists in the nurturing a working atmosphere that allow learning system of an organization to grow. In this context, following hypothesis can be assumed:

\section{Hla: HR-linked quality assurance system is progressively connected with learning system of an organization.}

Team linked with quality assurance involves people with multi-functional background, this collaboration allows them to share their knowledge with each other and work on the possible enhancement options (Zeng, Zhang, Matsui, and Zhao, 2017; Bakotić, Rogošić, 2017). Working in teams aids the knowledge system as individuals can share their experience and knowledge which they gained over the years. Quality assurance system also motivate employees to work with same procedural approach as they have common goal to achieve; this approach includes PDCA, a process used for business control and continuous improvement. All this support the knowledge system of an organization as the approach is same, goal is same and eventually employee display alike behavior (Knight, \& Harvey, 2015). Management need to make sure that resources are available so that training sessions can be conducted without any hassle; efficient training of employees allow them to learn ideology, methods and tools associated with quality assurance (Oh, Kuchinke, 2017; O’Neill, Sohal, Teng (2016). Researchers have also argued that knowledge system is stirred through social interface and is nurtured when employees feel empowered (Bakotić, Rogošić, 2017). Consequently, following hypothesis can be assumed:

HIb: HR-linked quality assurance system is progressively connected with knowledge system of an organization.

Development of novel product is very much progressively related with executing quality assurance measures, in comparison to other elements, there need to exist evenness between prevailing technological settings of an organization and the market (Askari, Sohrabi, 2017). Employees feel motivated when they are empowered, and this inspires them in bringing about improvement in the overall operations and product. Measures taken to inspire improvement can lead towards development of novel product and accordingly gratifying consumers. Moreover, organizations building teams with people from different functional background with the purpose of developing novel product; people associated with the team can share their diversified knowledge and accordingly work towards developing new idea and concept (Chiang, Hung, 2014). Building team can be regarded as an important factor which allows individual to show their creative side, which is significant aspect of developing a novel product (Hong et al., 2017). Teamwork also helpful in solving different problem creatively through brainstorming sessions, at the same time employees overall knowledge of the product or services also improved (Prajogo, 2016). Furthermore, empowering employees and distributing them into different team, fortifies the channels that allows smooth information flow, permits employee to make decision on their own and accordingly evaluate themselves, limits technical restriction and nurture creativity (Askari, Sohrabi, 2017). To be precise, organization needs to foster an environment which is built on trust, empowerment, and easy communication, at the same time making sure that required resources are available for appropriate and comprehensive training sessions. HR-linked quality assurance system facilitates organization in establishing such environment and make sure that required resources are at their disposal (O'Neill et al., 2016). Based on the above presented arguments, following hypothesis can be assumed:

\section{H1c: HR-linked quality assurance system is progressively connected with development of novel product.}

\section{Learning System of an organization}

There are very clear directions with respect to learning system as it consist of an environment which is conducive to collaboration as well as easy communication; key attribute associated with such a system is that, it provides a platform which allow employee to share ideas, progressiveness, commitment and lastly exchange of knowledge 
JOURNAL OF SECURITY AND SUSTAINABILITY ISSUES

ISSN 2029-7017/ISSN 2029-7025 (online)

2020 Volume 9 January

http://doi.org/10.9770/jssi.2020.9.3(20)

across various functions (Vicente et al., 2018). Similarly, it also influences the type of data collected, assess that information, presents the interpretation, and finally shared the same with end user (Biegelmeyer et al., 2017). Consequently, there is recurrent flow of knowledge within the organization in relation to learning system; at the same it also encourages employees to share their personalized knowledge regarding needs of the customer, technical part and resources of organization.

In this age of modernization, the degree of intricacy associated with organizational data is extraordinary, and it has become difficult for organization to manage the related information in a particular department. Subsequently, knowledge assimilation has become very much important for the progression of any novel venture of an organization. Based on the framework, learning system can be regarded as fundamental variable that outline the degree of knowledge assimilation viability. Past studies have also signified the importance of having a learning system and considered it as an essential element of the overall structure as well as the knowledge assimilation process (Guo et al., 2018; Fajar et al., 2018). In this context, developing a learning system can be considered an essential phase, in route to establishing a knowledge assimilation model. Ensuring common value and culture in organization, employee must show inclination to work by having social interface with each other which is built on the foundation of trust and impartiality. Organization with such type of atmosphere is also likely to encourage exchange of knowledge internally. Based on presented arguments, following hypothesis can be assumed:

\section{H2: Learning system of an organization is progressively connected with knowledge assimilation.}

\section{Knowledge Assimilation}

At first researchers advocated that knowledge assimilated is the source of rapid response capacity of the organization (Nonaka \& Toyama, 2015), afterwards experiential studies highlighted that knowledge assimilation aid in updating knowledge base of the organization and add new information from the external sources in the existing system (Eriksson, 2014). Along these lines, further research papers identify that knowledge assimilation can be regarded as an important tool to realize as well as fully comprehend the modifications associated with today's environment; at the same time it facilitate organization in sharing noteworthy knowledge with employees, which allow them better understand the changes. This signifies that knowledge assimilation can be utilized to correctly perceive the frequent environmental challenges and accordingly regulate the reply. Practically knowledge assimilation can play a vital role in reinforcing the strategic adaptability of an organization; with its capacity to realize and react to the preeminent environmental modifications by pointing out the available opportunities as well as highlighting threats, it can execute periodic strategic plans to capitalize new settings (Baškarada \& Koronios, 2018; Harrigan, 2017). In light of above presented arguments, following hypothesis can be assumed:

\section{H3: Knowledge assimilation is progressively connected with strategic adaptability.}

\section{Strategic Adaptability}

With respect to the existing unsettled environment, organization strategic adaptability evolves into the central ability for countering dynamic environmental challenges. Actually, organization can better understand their strategic adaptability via development of novel product and accordingly react toward perceive opportunities and intimidations. Past studies have advocated that the relation between strategic adaptability and development of novel product when situation is apparent to be unsettled, steps taken to overcome the turbulent environment must be coherent with the demands of market (Fantazy \& Salem, 2016). Development of novel product can be considered a very tactical decision in order to react towards environment changes. Through strategic adaptability, organization can better sense and comprehend the opportunities and intimidations presented by environment; accordingly they 
JOURNAL OF SECURITY AND SUSTAINABILITY ISSUES

ISSN 2029-7017/ISSN 2029-7025 (online)

2020 Volume 9 January

http://doi.org/10.9770/jssi.2020.9.3(20)

can draw the line of actions synchronizing it with investment decisions and establishing teams with multi-functional expertise so that novel product launch can be executed without any hassle. The scope of strategic adaptability is very much visible is smartphone industry, as the mobile technology keep updating, so company has to face consistent environmental changes and they adapt to these changes by bringing new headset and keep updating their technology (Suarez, Grodal 2015). Subsequently the development of novel product portrays the capability to be strategically adaptable, as organization able to perceive the new market opportunities and utilize the same by launching new product range or features to counter the competitions or changing consumer needs. Therefore, following hypothesis can be assumed:

\section{H4: Strategic adaptability is progressively connected with development of novel product.}

\section{Research Methodology}

Data was gathered by analyzing the Quality assurance system, its fundamental mechanism at its connection with operational proficiency of organization working in different ASEAN countries. Considering the scope of the study cross sectional instrument was used to collect the data, as it has far greater reach and very much apt in managing several variables (O’Neill, Sohal, Teng 2016).

Through literature review, different items and gauging parameters were recognized. Parameters used to gauge the HR-linked quality assurance system and strategic adaptability consists of items that were original. Quality assurance and its related practices have already been analyzed by several researchers and they have advocated its interconnected nature (Prajogo, 2016). HR-linked quality assurance and its practice were clustered into second order factor in order to ensure the originality of the research and minimize the repetition factor. Organization capacity of developing a novel product is reveal through habitual support of creative processes (Samson, Gloet, Singh, 2017). Based on endorsements of previous studies related with development of novel product (Fantazy, Salem, 2016), performance scores were utilized to evade any distort information; that is items used to gauge the performance of new product were used as proxy to measure the capacity of organization in developing novel product. Likert scale was used to measure the variables.

Initial draft of the survey instrument was pretested by managers associated with quality assurance department of different organization related with different industrial sectors. Idea was to remove any probable obscurities and accordingly make the alteration based on feedback. Detailed response was received from the managers and based on the recommendation's changes were made and the structure of the questionnaire was rectified.

Sample size consists of 1200 organizations operating in ASEAN countries. Organizations were selected from the database of ERIA (Economic Research Institute for ASEAN and East Asia). Letter was written attention to COO of selected organization, explaining the scope of study. It had the link to the survey instrument which can be filled online. Respondents were promised that summary of the result will also be shared with them in order to ensure that respondent has the required motivation to fill the questionnaire. Eventually 151 response were received which is $12 \%$ response rate and can be considered appropriate, but results cannot be generalized based on the response rate (Pedersen, Nielsen, 2014). As ERIA database include organizations with diverse industry sector and were operating in different countries, so generalization issue was alleviated.

Existence of common method variance was also examined; the common method to remove such uncertainties is by pre-testing the survey instrument which was done before the questionnaire was sent to the targeted organizations. In case the threat is severe to the study, variance can be accounted through one factor test (Podsakoff et al., 2012). 
JOURNAL OF SECURITY AND SUSTAINABILITY ISSUES

ISSN 2029-7017/ISSN 2029-7025 (online)

2020 Volume 9 January

http://doi.org/10.9770/jssi.2020.9.3(20)

Consequently, Harman's test was performed, and results reveal that single factor prototype had meager fit; hence common method variance cannot be considered a potent issue.

Responses were received from 7 countries which include: Indonesia, Malaysia, Thailand, Vietnam, Philippines, Singapore and Cambodia. Majority of the response was received from Indonesia and Malaysia that is response rate of $63 \%$ and $20 \%$ respectively, while rest of the targeted sample had a response rate of $17 \%$.

Diverse industry sector was included in the targeted sample. Industry distribution of 151 organizations participated in the study is as follow: 38 were related with service sectors, 25 were associated with exploration of oil and gas, 21 were related with Electronics, 17 were related with Textiles and Apparel, 14 were related with Information and Communications Technology (ICT), and remaining 36 were associated with different sectors. The diversity of the sample is very much fitting, the reason being the differentiating factor between service organizations and manufacturing firm is getting vague as both types of organizations are very much receptive to consumers as well as both ensure quality aspect with respect to their process and final output.

18 organizations had 50 or less employees, 70 organizations had employees within the range of 51 to 500,41 organizations had total employees in the range of 501 to 1000, and lastly 22 organizations with total employees more than 1000. Similarly 18 organizations had annual sales of 1 Million dollar or less, 40 organizations reported annual sales in the range of 1 Million to 5 Million dollar, 55 organizations had annual sales in between the range of 5 Million to 10 Million dollar, and lastly 38 organization had annual sales more than 10 Million dollar.

In order to investigate the construct validity, and subsequently the suggestion of Ibrahim et al. (2014), all parameter was examined through process validation. First reliability test was conducted using Cronbach's Alpha test. Followed by Uni-dimensionality of the construct was investigated, this was achieved through exploratory factor analysis were PCA (Principal component analysis) technique was used and by changing its coordinate varimax rotation was performed. Subsequently, the concluding modification of Uni-dimensionality was done by evaluation the scale using software Lisrel and CFA (confirmatory factor analysis). To be specific two measurement model related with HR-linked quality assurance were analyzed; at the same time one model related with operational proficiency was also examined. Table \# 1 reveal the numbers related with goodness of fit of the measurement model, as the result suggest measurement model has very acceptable fit. Findings from the second order test for HR-linked quality assurance also reveals that the factor loading as well as t-value is very much significant. Construct reliability for the processed scales are presented in Table 2 .

Confirmatory Factor Analysis also facilitate in examining convergent validity of the scale. As suggested by Christian et al. (2018) items to gauge the variables much have reliability exceeding 0.5 and factor loading should also be significant ( $p$-value $<0.05 \&$ t-value $>1.96)$. Based on these recommendations' items were detached.

Subsequently scales divergent validity was also examined. As suggested by Henseler et al. (2015), confidence intervals were built over the projected correlations amid two factors. Divergent validity will be realized if the internal does not consist of 1.0. Finding validated divergent validity of the scale as intervals does not include 1.0. Table 2 showcase variable correlation and average variance extracted. 


\section{JOURNAL OF SECURITY AND SUSTAINABILITY ISSUES \\ ISSN 2029-7017/ISSN 2029-7025 (online) \\ 2020 Volume 9 January \\ http://doi.org/10.9770/jssi.2020.9.3(20)}

Table 1. Variable correlation and average variance extracted

\begin{tabular}{|c|c|c|c|c|}
\hline \multirow[t]{2}{*}{ Goodness of fit } & \multicolumn{2}{|c|}{$\begin{array}{c}\text { HR-linked Quality Assurance Measurement } \\
\text { Model }\end{array}$} & \multirow{2}{*}{$\begin{array}{c}\text { Measurement Model for } \\
\text { previously developed new } \\
\text { product and operational } \\
\text { proficiency }\end{array}$} & \multirow[t]{2}{*}{$\begin{array}{l}\text { Structural } \\
\text { Prototype }\end{array}$} \\
\hline & First Order Model & Second Order Model & & \\
\hline$\chi 2 / \mathrm{df}$ (normed chi-square) & 1.702 & 1.691 & 2.201 & 1.983 \\
\hline $\begin{array}{l}\text { RMSEA (Root Mean Square Error of } \\
\text { Approximation) }\end{array}$ & 0.051 & 0.048 & 0.062 & 0.059 \\
\hline Akaike Information Criterion & 195.78 & 198.58 & 285.45 & 699.173 \\
\hline Saturated Model & 364.86 & 364.86 & 493.85 & 1601.198 \\
\hline Independent Model & 3491.48 & 2761.83 & 4581.94 & 7487.582 \\
\hline Parsimony GFI (Goodness of Fit Index) & 0.61 & 0.57 & 0.64 & 0.702 \\
\hline Parsimony NFI (Normed Fit Index) & 0.71 & 0.69 & 0.73 & 0.791 \\
\hline CFI (Comparative Fit Index) & 0.98 & 0.98 & 0.98 & 0.969 \\
\hline
\end{tabular}

Table 2. Path coefficients and t-value for each assumed hypothesis

\begin{tabular}{|c|c|c|c|c|c|c|c|c|c|c|c|}
\hline Constructs & Average & $\begin{array}{l}\text { Standard } \\
\text { Deviation }\end{array}$ & 1 & 2 & 3 & 4 & 5 & 6 & 7 & $\begin{array}{l}\text { Composite } \\
\text { Reliability }\end{array}$ & AVE \\
\hline Employee Training & 5.183 & 1.194 & 1 & & & & & & & 0.81 & 0.66 \\
\hline Empowering Employee & 4.892 & 1.302 & $0.527 * *$ & 1 & & & & & & 0.93 & 0.85 \\
\hline Collaboration & 4.652 & 1.492 & $0.542 * *$ & $0.537 * *$ & 1 & & & & & 0.94 & 0.87 \\
\hline Learning System & 5.394 & 1.295 & $0.298 * *$ & $0.172 * *$ & $0.352 * *$ & 1 & & & & 0.97 & 0.86 \\
\hline Knowledge Assimilation & 4.591 & 1.486 & $0.319 * *$ & $0.236 * *$ & $0.462 * *$ & $0.396 * *$ & 1 & & & 0.85 & 0.75 \\
\hline Strategic Adaptability & 4.473 & 1.467 & $0.179 * *$ & $0.139 * *$ & $0.328 * *$ & $0.392 * *$ & $0.536^{* *}$ & 1 & & 0.91 & 0.81 \\
\hline Development of Novel Product & 4.605 & 1.439 & $0.267 * *$ & $0.125 * *$ & $0.309 * *$ & $0.329 * *$ & $0.448 * *$ & $0.465 * *$ & 1 & 0.93 & 0.76 \\
\hline
\end{tabular}

Note: $* \mathrm{p}<0.05 ; * * \mathrm{p}<0.01$

C.R (suggested value $>0.7$ )

AVE (suggested value > 0.5) 
JOURNAL OF SECURITY AND SUSTAINABILITY ISSUES

ISSN 2029-7017/ISSN 2029-7025 (online)

2020 Volume 9 January

http://doi.org/10.9770/jssi.2020.9.3(20)

\section{Findings}

Structural Equation Model has been used to examine the assumed hypotheses. Lisrel software has been used to carry out the analysis and results are presented in Figure 2. It consists of path coefficients and t-value for each assumed hypothesis, $\mathrm{t}$-value with score higher than 1.96 will be significant at $\mathrm{p}$-value less than 0.05 and $\mathrm{t}$-value with score higher than 2.58 will be significant at p-value less than 0.01 . Structural prototype goodness of fit is presented in Table \# 1. Results accumulated showcased very acceptable value and implies that the prototype portray reasonable fit [Katerina M. Marcoulides \& Ke-Hai Yuan, (2016)], which further validates the assumed hypotheses.

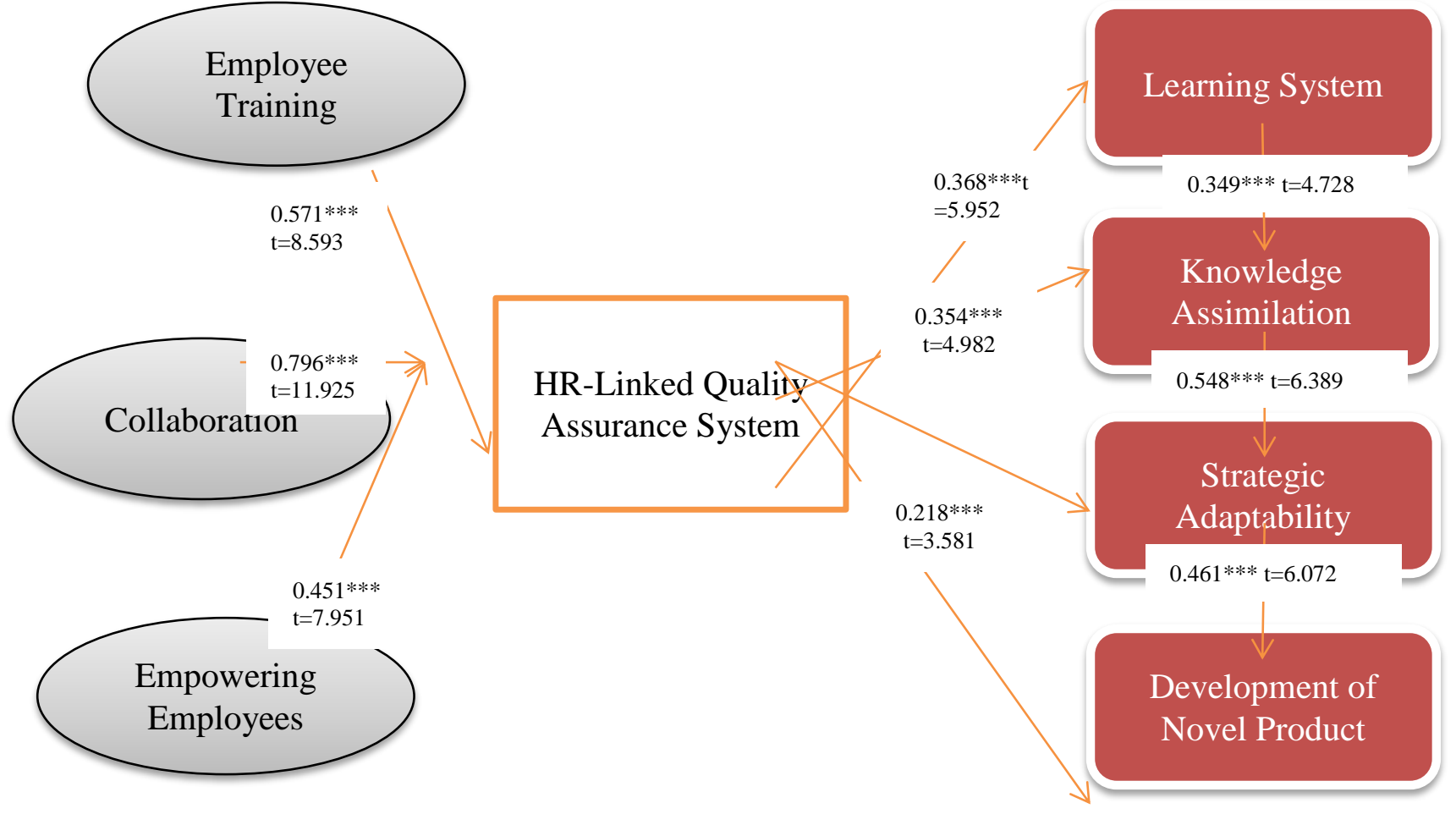

Figure 2. Results of analysis

\section{Discussion}

The aim of this research paper was to examine the connection between HR-linked quality assurance system, learning system, knowledge assimilation, strategic adaptability and development of novel product, and accordingly recognize the relationship that materializes between these constructs.

Based on assumed hypotheses HR-Linked quality assurance system has a progressive connection with learning system, knowledge orientation and development of novel product, so the desirable results should emphasize the significance of HR-linked quality assurance system for an organization. Findings of the research paper relate HRlinked quality assurance system with operation proficiency which include development of novel product, thus backing up the results by presenting an argument that HR-linked quality assurance system can play a significant role in improving organizational performance with the help of other variables (Quang et al., 2016; Gremyr et al. 2019). Research paper in hand specifies that there is progressive connection between quality assurance system and creativity via experiential evidence. 
JOURNAL OF SECURITY AND SUSTAINABILITY ISSUES

ISSN 2029-7017/ISSN 2029-7025 (online)

2020 Volume 9 January

http://doi.org/10.9770/jssi.2020.9.3(20)

Findings are very much compatible with prior studies validating that HR-linked quality assurance system allows organization to conduct training sessions for employees which improves their knowledge and increase employees' involvement by empowering them which further strengthens learning system that assist in assimilating knowledge all through the organization (Liang et al. (2015). Research paper also enhances the scope of knowledge by promoting a connection between collaboration between employees and learning system that lead towards creation of knowledge and ultimately knowledge assimilation. Results also validate the theoretical framework which emphasizes the worth of an organization which has a mechanism that encourages teamwork having multi-functional expertise which further stimulates knowledge assimilation and allow this proficiency to grow until it becomes a routine for developing novel product. Lastly through knowledge assimilation, HR-Linked quality assurance system is progressively but indirectly connected with strategic adaptability. Findings very much validate the suggestion of Kumar, \& Sharma [2017] that organization that has a defined quality assurance system is likely to establish efficient strategic adaptability than organization that does not have quality assurance system reason being quality assurance system gives better process control. Hence quality assurance activities and assimilated knowledge enhances organization capacity to better respond to the environmental changes strategically.

Study also expands the existing literature related with operational proficiency and its connection to Human resource management and quality assurance system (Garavan, Shanahan, Carbery \& Watson, 2016). Results signify the importance to give more consideration to HR-linked quality assurance system in organizations that aspire to build their operational proficiency. Similarly, variables like Human resource management, quality assurance system and development of novel product can be connected in order to attain flexibility which allows organization to counter the dynamic demands of existing competitive environment.

Managers can gain significantly from the study as it suggests methods to nurture as well as categorize important points in executing quality assurance system which allows organization to be more adaptable strategically and accordingly work towards developing novel product. Findings have provided solid bases for implementing quality assurance system as recognized connection with operational proficiency very much backs the decision of implementing quality assurance system. Results further emphasized the value of devoted efforts and consideration by managers to execute HR-connected practices as suggested by quality assurance system, as these activities will ultimately lead towards development of novel product. Results also vindicate the idea of assimilating two variables that is HR-linked quality assurance system and development of novel product, allows organizations to respond to the dynamic changes of the environment efficiently, as existence of the organization is very much dependent how it counter these changes.

Managers also need to foster a culture which allows employees to actively participate; this can be achieved by conducting training sessions and empowering them. Findings also highlight the significance of collaboration by establishing teams. In order to enhance the efficiency of team, great responsibly lies with manager to understand nitty-gritty associated with teamwork which include trust, mechanism, procedures, cracking problems, giving adequate space and time management; these elements are very essential in nurturing an environment that very much guarantee that the desired objectives will be achieved which are expected from the team that was created.

Efficiency of HR-linked quality assurance system is very much dependent on having knowledge management system, so manager need to give equal importance to all the related factors that include learning system, knowledge assimilation and strategic adaptability.

Manager also need realize the importance of building operational proficiency while executing quality assurance measures. Findings have revealed that investing in operational proficiency such as development of new product will 
JOURNAL OF SECURITY AND SUSTAINABILITY ISSUES

ISSN 2029-7017/ISSN 2029-7025 (online)

2020 Volume 9 January

http://doi.org/10.9770/jssi.2020.9.3(20)

allow organization to appropriately respond environmental changes. Significance of strategic adaptability also cannot be overlooked as it very much leads towards establishing particular operational proficiency and allow organization to counter unsettles environment, therefore it can be identified as one of the pillar through which organization can develop competitive edge and sustain high level of performance.

\section{Limitations}

Research paper also has its limitations. Study has concentrated on strategic aspect of an organization; variables like learning system, strategic adaptability and knowledge assimilation are built over long period of time so their influence may not visible in the near future. Similarly, research paper has not taken the impact of assessing employee performance or employee retribution while studying HR-linked quality assurance system. Moreover, results cannot be generalized due to low response rate. Data was collected through self-reporting, so possibility of respondent sharing his beliefs is always there, which means respondent might miss sharing actual detail and data might be low on objectivity. Lastly the impact of any control variable was not considered while discussing the connection between the variables in the literature view. Therefore, parsimonious model was selected in order to achieve coherent and meaningful results.

\section{Conclusion}

The focal point of the research paper was to examine the connection between HR-linked quality assurance system and development of novel product by establishing operational proficiency. Results gathered recognize a sequence of connection confirming that HR-linked quality assurance system is progressively associated with establishing operational proficiency and subsequently with organizations flexibility.

Research paper also validates the significance of HR-linked quality assurance system in the organization. It was observed that activities associated with HR-linked quality assurance system have some key features which are tough to emulate. Garcia (2017) emphasized that the more superior environmental dynamism is, operational proficiency will have far more reaching influence. Future research paper can greatly gain if they can include environmental dynamism as controlling factor while analyzing other relationship, as the study will be able to present more accurate image and allow us to better understand the capacity of quality assurance system inspiring operational proficiency and ultimately assuring success.

\section{References}

Al Ahbabi, S. A., Singh, S.K., Balasubramanian, S., Singh Gaur S.S. (2019). Employee perception of impact of knowledge management processes on public sector performance. Journal of Knowledge Management, 1367-3270. https://doi.org/10.1108/JKM-08-2017-0348

Askari, S.S., Sohrabi, S. (2017). Investigating the relationship between quality management and organizational innovation. Investigation, Ciencia y Technology, 1844-1853 ISSN-e 2462-9006,

Bakotić D., Rogošić, A. (2017). Employee involvement as a key determinant of core quality management practices. Total Quality Management \& Business Excellence, 28(11-12), 1209-1226. https://doi.org/10.1080/14783363.2015.1094369

Barney, L. (1991). Firm resources and sustained competitive advantage. Journal of Management, 17, 99-120. https://doi.org/10.1177\%2F014920639101700108 


\section{JOURNAL OF SECURITY AND SUSTAINABILITY ISSUES ISSN 2029-7017/ISSN 2029-7025 (online) 2020 Volume 9 January http://doi.org/10.9770/jssi.2020.9.3(20)}

Baškarada, S., Koronios, A. (2018). Strategies for maximizing organizational absorptive capacity. Industrial and Commercial Training ISSN: 0019-7858 https://doi.org/10.1108/ICT-07-2017-0060

Biegelmeyer, U.H., Camargo, M.E., Craco, T., Galelli, A., Fernandes, A.M., Biegelmeyer, S.C. (2017). The Relationship between Market Orientation, Learning Orientation and Organizational Performance in the Development of New Products. International Journal of Business Management and Economic Research (IJBMER), 8(5), 1052-1059.

Boon, C., Hartog, D.N.D., Lepak, D.P. (2019). A Systematic Review of Human Resource Management Systems and Their Measurement, Journal of Management https://doi.org/10.1177\%2F0149206318818718

Cardoso, P.P., Swan, A.D., Mendes, R. (2018). Exploring the key issues and stakeholders associated with the application of rainwater systems within the Amazon Region. Entrepreneurship and Sustainability Issues, 5(4), 724-735. https://doi.org/10.9770/jesi.2018.5.4(2)

Chiang, Y., Hung, K.P. (2014): Team control mode, workers' creativity, and new product innovativeness. R\&D Management, 44, $124-136$. https://doi.org/10.1111/radm.12044

Danneels, E., Vestal, A. (2018). Normalizing vs. analyzing: Drawing the lessons from failure to enhance firm innovativeness. Journal of Business Venturing; Available online 9 October 2018 https://doi.org/10.1016/j.jbusvent.2018.10.001

Davies, A., Dodgson, M., Gann, D. (2016). Dynamic Capabilities in Complex Projects: The Case of London Heathrow Terminal 5. Project Management Journal, 47(2) https://doi.org/10.1002/pmj.21574

Eriksson, T. (2014). Processes, antecedents and outcomes of dynamic capabilities. Scandinavian Journal of Management, $30,65-82$. https://doi.org/10.1016/j.scaman.2013.05.001

Fajar, W.N., Paulus, I., Greis, S, Bode, L (2018). Employee Fit, Trust, Knowledge Sharing and Innovation Capabilities: Empirical Study on Indonesia Creative Industry. Journal of international conference proceeding, 1(2) https://doi.org/10.32535/jicp.v1i2.235

Fantazy, K.A., Salem, M. (2016): The value of strategy and flexibility in new product development, Journal of Enterprise Information Management, 1741-0398. https://doi.org/10.1108/JEIM-10-2014-0102

Fay, D., Shipton, H., West, M.A. Patterson, M. (2015). Teamwork and Organizational Innovation: The Moderating Role of the HRM Context. Creativity and Innovation Management, 24, 261-277. https://doi.org/10.1111/caim.12100

Gabriel, A.S., Cheshin, A., Moranc, C.M., van Kleef, G.A. (2015). Enhancing emotional performance and customer service through human resources practices: A systems perspective. Human Resource Management Review, 26(1), 14-24

https://doi.org/10.1016/i.hrmr.2015.09.003

Garavan, T., Shanahan, V., Carbery, R., W atson, S. (2016). Strategic human resource development: towards a conceptual framework to understand its contribution to dynamic capabilities. Human Resource Development International, 9(4)

https://doi.org/10.1080/13678868.2016.1169765

Garcia, A.E.G. (2017). The competitive intelligence and the development of dynamic capabilities in organizations. Iberoamerican Journal of Strategic. 16(1). https://doi.org/10.5585/ijsm.v16i1.2439

Gremyr, I., Elg, M., Hellström, A., Martin, J., Icon, Witell, L. (2019): The roles of quality departments and their influence on business results. Total Quality Management \& Business Excellence. https://doi.org/10.1080/14783363.2019.1643713

Harrigan, K.R. (2017). Strategic Flexibility and Competitive Advantage; Business Policy and Strategy. Operations Management; Oxford Research Encyclopedias. https://doi.org/10.1093/acrefore/9780190224851.013.2

Henseler, J., Ringle, C.M., Sarstedt, M. (2015). A new criterion for assessing discriminant validity in variance-based structural equation modeling. Journal of the Academy of Marketing Science, 43(1), 115-13. https://doi.org/10.1007/s11747-014-0403-8 


\section{JOURNAL OF SECURITY AND SUSTAINABILITY ISSUES ISSN 2029-7017/ISSN 2029-7025 (online) \\ 2020 Volume 9 January \\ http://doi.org/10.9770/jssi.2020.9.3(20)}

Hong, J., One-Ki, D., Lee, Suh, W. (2017). Creating knowledge within a team: a socio-technical interaction perspective. Knowledge Management Research \& Practice, 15(1), 23-33. https://doi.org/10.1057/kmrp.2015.27

Jermsittiparsert, K., Namdej, P., \& Somjai, S. (2019). Green Supply Chain Practices and Sustainable Performance: Moderating Role of Total Quality Management Practices in Electronic Industry of Thailand. International Journal of Supply Chain Management, 8(3), 33-46.

Khalil S.R., \& Mehmood, K.K. (2018). Knowledge Management, Emotional Capability, Teamwork, and Innovativeness: Mediating Role of Organizational Learning. Review of Economics and Development Studies, 4(2) https://doi.org/10.26710/reads v4i2.407

Knight, E., Harvey, W. (2015). Managing exploration and exploitation paradoxes in creative organizations. Management Decision, 00251747. https://doi.org/10.1108/MD-03-2014-0124

Kumar, V., Sharma, R.R.K. (2017). An empirical investigation of critical success factors influencing the successful TQM implementation for firms with different strategic orientation, International Journal of Quality \& Reliability Management; ISSN: 0265-671X. https://doi.org/10.1108/IJQRM-09-2016-0157

Liang, H-Y., Shih, H-A., Chiang, Y-H. (2015). Team diversity and team helping behavior: The mediating roles of team cooperation and team cohesion. European Management Journal, 33(1), 48-59. https://doi.org/10.1016/j.emj.2014.07.002

Lin, C.-H., Sanders, K., Jian-Min, Shipton, H., Mooi, E.A. (2018). Market-sensing capability and the moderating role of national power distance. The International Journal of Human Resource Management https://doi.org/10.1080/09585192.2018.1474938

Longoni, A., Cagliano, R. (2016). Human resource and customer benefits through sustainable operations. International Journal of Operations and Production Management, 36, 1719-1740. https://doi.org/10.1108/IJOPM-11-2014-0564

Marcoulides, K.M., Yuan, K-H. (2016): New Ways to Evaluate Goodness of Fit: A Note on Using Equivalence Testing to Assess Structural Equation Models. Structural Equation Modeling: A Multidisciplinary Journal, 24(1), 148-153. https://doi.org/10.1080/10705511.2016.1225260

Moumen, Z., El Idrissi, N.E.A., Tvaronavičienė, M., Lahrach, A. (2019). Water security and sustainable development. Insights into Regional Development, 1(4), 301-317. https://doi.org/10.9770/ird.2019.1.4(2)

Nonaka, I., Toyama, R. (2015): The Knowledge-creating Theory Revisited: Knowledge Creation as a Synthesizing Process. The Essentials of Knowledge Management, 95-110. https://doi.org/10.1057/palgrave.kmrp.8500001

O’Neill, P., Sohal, A., Teng, C. W. (2016). Quality management approaches and their impact on firms' financial performance - An Australian study. International Journal of Production Economics; 171, Part 3, 81-393 https://doi.org/10.1016/j.ijpe.2015.07.015

Oh, S-Y. K. Kuchinke, P. (2017). Exploring the role of organizational learning activities in the quality management context. Leadership \& Organization Development Journal ISSN: 0143-7739 https://doi.org/10.1108/LODJ-11-2015-0259

Park S., Kim, E.-J. (2018): Fostering organizational learning through leadership and knowledge sharing. Journal of Knowledge Management ISSN: 1367-3270. https://doi.org/10.1108/JKM-10-2017-0467

Pedersen, M.J.,Nielsen, C.W. (2014). Improving Survey Response Rates in Online Panels: Effects of Low-Cost Incentives and Cost-Free Text Appeal Interventions. Social Science Computer Review; 34(2) https://doi.org/10.1177\%2F0894439314563916

Petrus, B. (2019). Environmental Dynamism: The Implications for Operational and Dynamic Capabilities Effects. Management Sciences, 24(1), 28-36 https://doi.org/10.15611/ms.2019.1.04

Pisano, G.P. (2017). Toward a prescriptive theory of dynamic capabilities: connecting strategic choice, learning, and competition; Industrial and Corporate Change, 26(5), 747-762 https://doi.org/10.1093/icc/dtx026

Podsakoff, P.M., MacKenzie, S.B., Podsakoff, N.P. (2012). Sources of Method Bias in Social Science Research and Recommendations on How to Control. Annual Review of Psychology, 63, 539-569. https://doi.org/10.1146/annurev-psych-120710-100452 


\section{JOURNAL OF SECURITY AND SUSTAINABILITY ISSUES ISSN 2029-7017/ISSN 2029-7025 (online) \\ 2020 Volume 9 January \\ http://doi.org/10.9770/jssi.2020.9.3(20)}

Prajogo, D.I. (2016). The strategic fit between innovation strategies and business environment in delivering business performance. International Journal of Production Economics, 171, Part 2, 241-249 https://doi.org/10.1016/j.ijpe.2015.07.037

Prajogo, D.I., Oke, A. (2016). Human capital, service innovation advantage, and business performance: The moderating roles of dynamic and competitive environments. International Journal of Operations and Production Management, 36, 974-994.

https://doi.org/10.1108/IJOPM-11-2014-0537

Quang, H.T., Sampaio, P, Carvalho, M.S., Fernandes, A.C., Binh, D.T., Vilhenac, E, (2016): An extensive structural model of supply chain quality management and firm performance. International Journal of Quality \& Reliability Management; ISSN: 0265-671X https://doi.org/10.1108/IJQRM-11-2014-0188

Ringle, C.M., Sarstedt, M., Mitchell, R., Gudergan, S.P. (2018). Partial least squares structural equation modeling in HRM research. The International Journal of Human Resource Management https://doi.org/10.1080/09585192.2017.1416655

Samson, D., Gloet, M., Singh, P. (2017). Systematic Innovation Capability: Evidence from Case Studies and a Large Survey. International Journal of Innovation Management, 21(07), 1750058. https://doi.org/10.1142/S136391961750058X

Schilke, O. (2014). On the contingent value of dynamic capabilities for competitive advantage: the nonlinear moderating effect of environmental dynamism, Strategic Management Journal, 35, 179-203. https://doi.org/10.1002/smj.2099

Shafiq, M., Lasrado, F., Hafeez, K. (2017). The effect of TQM on organizational performance: empirical evidence from the textile sector of a developing country using SEM. Total Quality Management \& Business Excellence, 30(1-2).

https://doi.org/10.1080/14783363.2017.1283211

Su, H.C., Linderman, K. (2016). An Empirical Investigation in Sustaining High-Quality Performance. Decision Sciences, 47, 787-819 https://doi.org/10.1111/deci.12210

Suarez, F. F., Grodal, S. (2015). Mastering the 'Name your product category’ game. MIT Sloan Management Review, 56, 23 -29.

Teece, D.J, (2018). Business models and dynamic capabilities. Long Range Planning, 51(1), Pages 40-49 https://doi.org/10.1016/j.lrp.2017.06.007

Vegera, S., Malei, A., Trubovich, R. (2018). Accounting development of natural resources in organizations carrying out the disposal of municipal waste and biogas extraction in the context of the "green" economy. Entrepreneurship and Sustainability Issues, 6(1), 211-225. http://doi.org/10.9770/jesi.2018.6.1(14)

Vicente, M., Figueiredo, A., Rodrigues, A.M. (2018). Capabilities and innovation: the moderating effect of environmental turbulence. European Journal of Applied Business and Management, 4(4)

Wilden, R., Gudergan, S.P. (2015). The impact of dynamic capabilities on operational marketing and technological capabilities: investigating the role of environmental turbulence. Journal of the Academy of Marketing Science, 43(2), 181-19. https://doi.org/10.1007/s11747-014-0380-y

Wrona, M. (2019). Organizational Effects and Measurement of Strategic Flexibility; Management. Theory and Practice / University of Management in Warsaw, 1(27), 11-20. 
JOURNAL OF SECURITY AND SUSTAINABILITY ISSUES

ISSN 2029-7017/ISSN 2029-7025 (online)

2020 Volume 9 January

http://doi.org/10.9770/jssi.2020.9.3(20)

Chayanan KERDPITAK is a Lecturer of Doctor of Philosophy Program in Development Administration, Suan Sunandha Rajabhat University, Thailand. Her research areas are Public and Private Administration, Development Administration, and Leadership.

Chanathat BOONRATTANAKITTIBHUMI is a Lecturer of King Moungkut's Institute of Technology, Prince of Chumphon Campus, Thailand. His research areas are in Management, Social Enterprise, and Organizational Behavior.

ORCID ID: orcid.org/0000-0002-9667-3730

Register for an ORCID ID:

https://orcid.org/register

This work is licensed under the Creative Commons Attribution International License (CC BY). http://creativecommons.org/licenses/by/4.0/

c) (i) Open Access 